\title{
Which Space? Whose Space? An Experience in Involving Students and Teachers in Space Design
}

\begin{abstract}
To date, learning spaces in higher education have been designed with little engagement on the part of their end-users. In this paper, we present the results of a research conducted in a UK University, which aimed to understand how students and teachers conceptualise learning spaces, if they are given the opportunity to do so. A number of these end-users were involved in creative design workshops. During these workshops, participants were encouraged to critique a space prototype (the 'Cube') and to re-design it according to their own ideas and vision of an optimal learning space. Findings suggest that an active involvement of end-users in space design endows these users with powers of reflection on the pedagogical process, which can usefully be harnessed for the actual creation and innovation of learning spaces.
\end{abstract}

Keywords: learning spaces, participatory design, large classroom, students' participation, active learning

\section{Preamble}

This article is about end-users' participation and agency in the design of learning spaces. Specifically, it revolves around the question: how different would a learning space be, if we were to integrate both teachers' and students' insights into its design? Starting with a literature review on the impact space has on both students and teachers in the learning and teaching process, we continue by considering how these end-users, given the agency to contribute, can usefully become definers of learning spaces. The paper continues by highlighting a specific research method adopted to respond to the research question, 'participatory design'. This is followed by an illustration of the most relevant findings before we argue that the value of the research is, in the originality of the approach adopted, in involving end-users in both talking about and actually practising the design of learning spaces. We conclude by discussing possible future research developments by arguing in favour of a type of learning space design that is equally dialogic and inter-professional.

\section{The issue of learning spaces}

Until recently, research in higher education has not focussed much on the issue of the physical spaces in which learning and teaching occur, as the focus has traditionally been on pedagogical practice, policy and curriculum design (Temple 2008). However, following 
recent and current changes within the sector (Kehm and Teichler 2013), the topic of learning spaces has become increasingly central, especially in terms of their possible impact on both learners and teachers, and their pedagogical encounters (Park and Choi 2014; Brooks 2012; Scott-Webber et al. 2014). Indeed, learning spaces have recently become a 'trendy' topic (Johnson et al. 2015; Temple 2008); however, evidence indicates that still much research is needed in this area, particularly in terms of when and how pedagogical practice can inform the space design process (Könings, Seidel, and Merriënboer 2014; Jamieson 2003). In this paper, we present a user-centred perspective for researching learning spaces by focussing on how end-users' perceptions of these spaces can contribute to their actual design. We provide evidence that supports arguments in favour of designing learning spaces through the active participation of both teachers and students. We believe that by promoting this form of grass-roots engagement, universities might be able to promote the construction of learning spaces, which are actually meaningful and useful for their end-users. Furthermore, the opportunity to conduct systematic research into the design process has generated insights into how students and teachers perceive the learning process, and how these perceptions may be used in the design of learning spaces.

We make use of a research method that actively involves both students and teachers in experimenting with the design of a learning space - participatory design. Bligh (2014) argues that involving end-users in reflecting about the design process may eventually lead to the construction of more meaningful, innovative and effective learning spaces. As importantly, Barnett and Temple (2007) state that this kind of approach encourages a more desirable participatory governance of HE.

\section{The influence of space design on its end-users, and vice versa}

Until recently, learning spaces have been designed according to the traditional paradigm of row-by-row seating, where a teacher is positioned on a podium at the front, facing a substantial number of students and 'transmitting' knowledge in a top-down fashion (Beichner 2014). In this kind of setting, the single focal point at the front of the room conveys an implicit message of power, with the teacher having the entitlement to speak, while the students listen in a passive, non-participatory manner (Van Note Chism 2006).

This type of layout is still arguably the most common in universities today but it fails to respond to emerging learner-centred pedagogies (Jessop, Gubby, and Smith 2012). It seems contradictory to suggest that teachers should promote active and collaborative learning in this kind of settings (Scott-Webber 2013). Students would struggle to collaborate with each other 
and the teacher. Similarly, Van Note Chism (2006) suggests that this can be better achieved by providing a room that can comfortably accommodate a smaller number of students around square or round tables, with chairs positioned on each side to encourage teamwork or group discussions. A number of authors argue that higher education institutions are increasingly supporting active and learner-centred pedagogies; as a consequence, new, more flexible learning spaces are being created to facilitate these (Miller-Cochran and Gierdowski 2013; Beichner 2014; Pederby 2014; Park and Choi 2014). This is in response to evidence that suggests that learning space design has an influence on how its users conceptualise and enact their learning (Jamieson et al. 2000; Beichner et al. 2000; Crook and Mitchell 2012; Park and Choi 2014). Jessop et al. (2012) found that space has an impact on how teachers perceive their teaching role, either as promoters of collaboration and creativity, or as constrainers. Similarly, Brooks (2012) demonstrated that teachers' and students' behaviours change according to the design and structure of the learning spaces, especially if these are underpinned by technology. Indeed, by relating to Brooks' research, some authors (Radcliffe 2009; Reushle 2012; Bligh and Pearshouse 2011) argue in favour of interweaving pedagogy and technology in the design of learning spaces for a positive impact on the pedagogical process itself.

However, the literature says very little about 'who' should help to shape the learning spaces: should it be only the architects and engineers? Or should the end-users have a more active role in the design and evaluative process? We wish to argue for the latter by basing our argument on the work conducted by scholars such as Könings et al. (2014); Sherringham and Stewart (2011) and Leijon (2016). These authors all clearly indicate how learning spaces design influence the pedagogical encounters, thus enforcing the need for involving them in more participative dialogical discussions when designing space.

A study conducted by Park and Choi (2014) highlights how students' perceptions of space impacts on the pedagogical process. One of the authors' most interesting findings was that students identified the existence of a 'golden zone' and a 'shadow zone' within the physical learning space. The term 'golden zone' indicates those seats which students consider to be optimal for learning in that they: (i) facilitate good eye-contact and a better interaction with the teacher; (ii) support concentration and motivation for longer periods of time; and (iii) guarantee the best view of the screen/whiteboard, decreasing without the dangers of being distracted. Students in the study clearly suggested three main features that should transpire when designing learning spaces: closeness to the teacher; an augmented sense of belonging and engagement; and good visibility. These findings point towards the potential usefulness of involving students in the design of learning spaces. 
Leijon (2016), when arguing about space design, makes use of Halliday's meta-functional theory by building on the work by Kress and Leeuwen (2005), Ravelli (2000) and Stenglin (2009). She argues that space conveys potential meanings to its users at the level of three meta-functions. The first, the 'ideational', concerns the 'vision', that is to say the users' perceptions of how space should/could facilitate learning. The second, the 'textual', concerns the way in which different learning spaces are organised consistently and coherently to support the first function. The third function, the 'interpersonal', concerns how space becomes a motivational factor in enabling positive learning and teaching interactions. Leijon's work provides a framework that can help in the design and evaluation of the synergetic relation between pedagogy, space and end-users. Significantly, it signals how the organisation of space can impact the latter's perceptions of the learning and teaching process. We make use of this framework as a heuristic device later in the paper for data reporting (see findings sections), as we consider it a useful lens through which to organise complex data sets.

\section{Participatory design as a method for designing learning spaces}

Educational literature seems to indicate that we should understand learning spaces design through an analysis of the interactions, habits and perceptions of its main users (Bligh 2014; Boys 2011; Cerratto-Pargman, Järvelä, and Milrad 2012; Williams 2014; Woolner 2009). In our research, we adopted a holistic approach to the design of learning spaces by utilising students and teachers' direct input into the space design process: participatory design. We were originally inspired by an experiment made at Lincoln University in the UK. In that institution, in 2013, the space planning team facilitated a workshop involving students and teachers in the space design process. However, differently from the Lincoln University experiment, in our research we did not simply encourage end-users to express their views on space but to actually draw what they thought might be effective learning spaces for their existing pedagogic encounters. This method was originally conceived in Scandinavia (Schuler and Namioka 1993) to understand how learning technologies could improve the work environment. Over the years, participatory design has increasingly been used in an array of domains, from health services to architecture and, more recently, education (CerrattoPargman, Järvelä, and Milrad 2012; Bonsignore et al. 2013; Könings, Seidel, and Merriënboer 2014; Woolner 2009; Craft 2013). 
Simply put, participatory design is both a philosophy and a set of research practices and tools that aim to make end-users active participants in the design process (Schuler and Namioka 1993). By doing so, users become not only participants in the process but also experts and partners, whose voices are jointly considered to be significant in the creation of learning spaces. Woolner (2009) argues about the positive impact that participatory design may have when building schools for the future. In a similar way, Bligh (2014) argues that the participatory process injects initiative, enthusiasm and collaboration between architects and end-users, thus fostering a sense of ownership with regards to the end product. Moreover, participatory design can be seen as an empowering tool which aligns well with the current efforts of promoting a more collaborative culture within the higher education sector (Temple and Barnett 2007). Our research is firmly embedded in the participatory design philosophy.

\section{Research design and methodological orientation}

The research took place in a medium-to-large university in the South-East of England, between November 2014 and May 2015. After obtaining ethical clearance from the institution, the researchers contacted a number of students (all course representatives), ultimately obtaining the support of sixteen of them. Their age range was between nineteen and thirty-five, with seven men and nine women. Similarly, the researchers managed to secure twenty-two members of teaching staff, across a number of disciplinary areas. Of these, ten were men and twelve were women, at different stages in their career. The researchers organised data collection through 'sandpits', thus involving the participants not only in talking about learning spaces but re-designing them too. All data was anonymised and the recordings of the comments made during the sandpits were analysed by using a thematic approach developed using the software NVivo $9 \circledR$ (Fereday and Muir-Cochrane 2006). The research is aligned with a constructivist paradigm, which is based on the principles of participatory action research and ethnography. This is participatory because the researcher participates throughout the research process as an active participant and informer, whose aim is to involve participants in discussions, clarify doubts (Kemmis, McTaggart, and Nixon 2014) and help to establish links between the design process, the space characteristics and pedagogy. It is ethnographical because the researcher is actively immersed in the task of observing people's actions and behaviours, whilst being mindful of not influencing their opinions and perceptions (Leijon 2012; Melhuish 2011). The principle and practice of the researcher as both an active informer and an external participant was carefully discussed with 
the participants to clarify possible ethical issues deriving from the researchers' involvement (Craft 2013).

Normally, participatory design research may include observations, surveys, informal interviews and participation in focus groups (Muller and Druin 2003; Schuler and Namioka 1993). For this particular research, we decided to use 'sandpits' (Frohlich, Lim, and Ahmed 2014). 'Sandpits' are creative, design-driven focus-groups, where participants are stimulated by the narrative of a scenario around the use of a particular product, object or artefact, and are subsequently encouraged to discuss, critique and re-design. The research process took place in two stages.

In the first stage, participants were provided with three visual scenarios, which the researchers carefully explained to the participants to minimise any possible misunderstanding of the task. The scenarios were inspired by the literature on the design of learning spaces (Boys 2011; Radcliffe 2009; Bligh and Crook 2016) and emerging trends in space design in higher education (Beichner et al. 2000; JISC - Joint Information Systems Committee 2006; Pederby 2014; Oblinger 2006; Neary et al. 2010). A first scenario suggested the idea of a fairly inflexible learning space. The participants were presented with the 'Cube', a prototypical learning space in the form of a square, to suggest a sense of closeness between the lecturer and students (A and B in Figure 1). The layout was influenced by the typical row-by-row setting (A and I in Figure 1), with a podium where the lecturer stands (B in Figure 1). The seating space was made up of individual seats, with reclining backs to adapt to students' postures for better visualisation of the projector screen. A second scenario was related to the pedagogic practices and how it was conducted in the 'Cube'. The lecturer was positioned at the centre the 'Cube', thus acting almost as a performer on a stage (B in Figure 1), in a teacher-centred style. However, the scenario allowed for some collaborative work by means of rotating seats ( $\mathrm{F}$ and $\mathrm{G}$ in Figure 1). A third scenario related to technology. The 'Cube' was designed with four projector screens, one on each side above the lecture's head (D in Figure 1). The idea was to ensure that all students could see the lecturer, thus providing a level of immersion and engagement in the pedagogic process ( $\mathrm{C}$ in Figure 1). The lecturer was endowed with a forty-inch tablet ( $\mathrm{J}$ in Figure 1), which enabled the management of a slide presentation and the control of the sound level, light intensity and room temperature. Students were provided with individual tablets ( $\mathrm{H}$ in Figure 1) for interaction with the teacher through the use of an electronic voting system, a digital whiteboard and the use of social media channels. A socket for each table and an area to place bags and coats were also part of this scenario. 


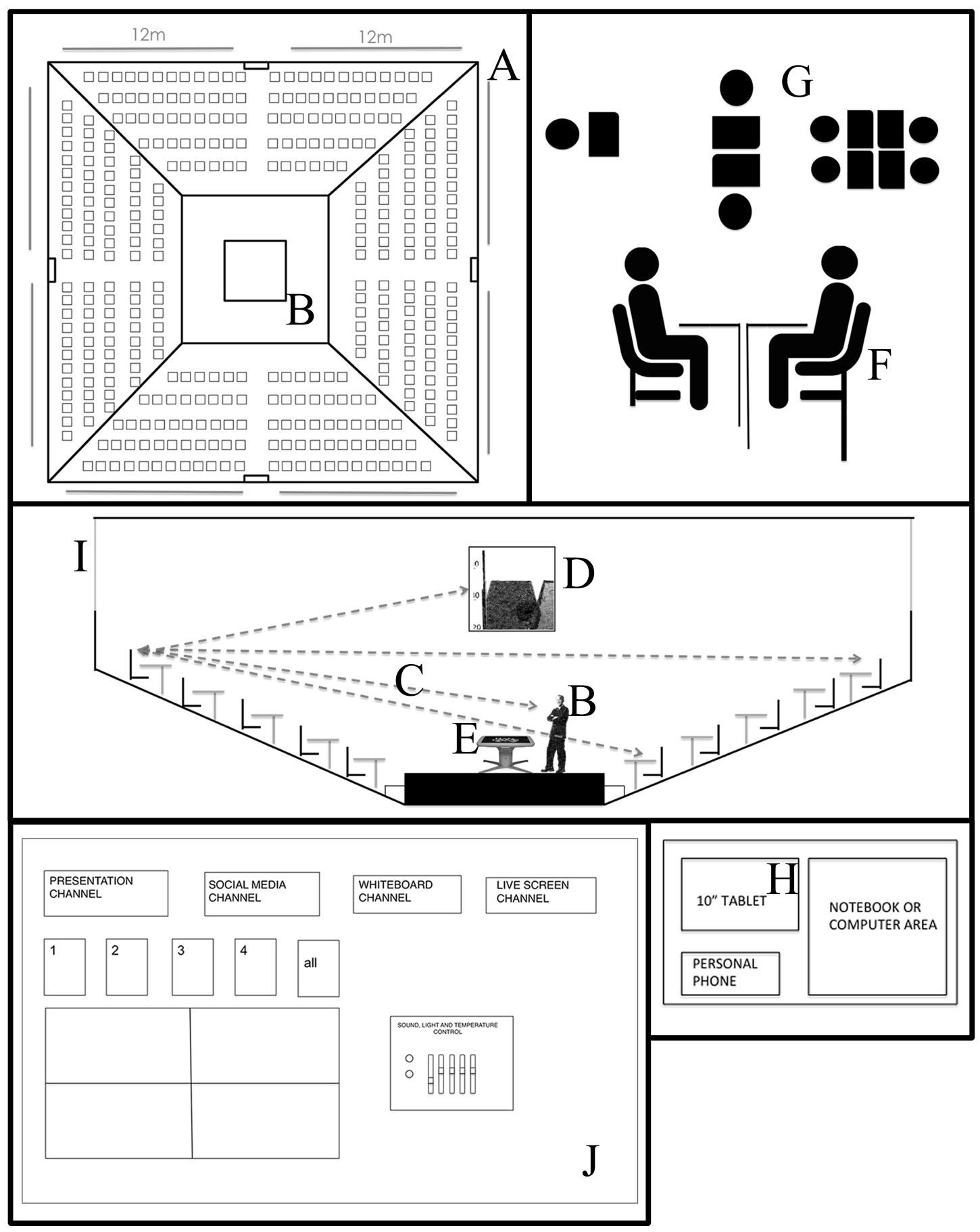

Figure 1. Screenshots of the images used to support the narrative during the 'sandpits'

The second stage consisted in the re-design of the 'Cube', through the use of four 'sandpits', with the teachers arranged in equal groups sitting around seven design tables, and the students gathered around five. Each group was made, as far as possible, of four participants to maximise participation; however, students and teachers were separated to minimise the emergence of unwanted power dynamics. 
Each 'sandpit' had a maximum duration of one hour and was divided into four phases. In the first phase, the nature and aims of the 'sandpits' were presented by the researchers. This took about five minutes. In the second phase, a researcher illustrated what might mean to learn and teach in the 'Cube' through the use of a background story centred around two fictitious characters. For the teachers, the story was based on the experience of lecturing in the 'Cube' narrated by John Lock, a Professor in Archaeology at Bloom's University (see appendix one); for the students the fictitious character was Richard Perry, an archaeology student at the same university. Whilst reading the contextual narrative, the narrator presented images of the 'Cube' showing details of how students and teachers would normally behave within that space (Figure 1). This usually took around fifteen minutes. In the third phase, each group had time to discuss and reflect on the presentation of the 'Cube'. Participants were given fifteen minutes to discuss the 'Cube' and write down what they would like to keep, lose or change from the original configuration. This strategy provided each group with the opportunity of discussing features of the space by focusing on what they liked or disliked and highlighting the rationale for their decisions.

Participants were subsequently given a A3-sized sheet and sticky notes to capture their thinking and, in the fourth phase, they were asked to re-design the 'Cube' by drawing sketches which reflected what had emerged from the discussions, in creative and collaborative ways (Craft 2013). At each design table, participants had at their disposal thirty photos of design furniture and educational technology solutions. These provided frames of reference for those who might feel unduly challenged by the exercise and needed some support. Scissors, sticky tape, coloured pencils, markers and a flipchart were made available, with a view to replicating a real design environment. This activity lasted until the end of the session, culminating with the group having to give a different name to the 'Cube', which, in their minds, best represented the re-designed space. Data, in the format of sticky notes and sketches was collected. This data was integrated by audio-recordings of the 'sandpits' to capture the richness of the exercise.

\section{Findings}

Stimulated by the layout of the 'Cube' and the clarifications provided by the researchers, both students and teachers creatively engaged in the re-design process at a similar level. However, the two groups of users demonstrated a level of difference in terms of perceptions, needs and uses of learning spaces, thus confirming findings by Jessop et al. (2012) that suggest different experiences influence how users perceive learning spaces design. 
Findings were analysed through Leijon's framework (2016) which was used as a heuristic device for effective scoping and organisation of the data. Although interconnected, in the following sections, the three communicative functions of learning spaces (ideational, textual and communicative) are presented separately to keep in line with the framework itself. Inevitably, the full richness of the data cannot be reported in the limited space of this article. We have therefore chosen the most salient results.

\section{The ideational function}

As mention earlier, the 'ideational' function relates to the end-users' perception of how space should/could facilitate learning. A first general impression of the 'Cube' was that it was a very different space from what the end-users were normally accustomed to in their pedagogical encounters. Words such as 'strange', 'disruptive' and 'innovative' were used, as participants discussed the prototype. Participants detected little familiarity with the structure, apart from identifying some resemblance with the 'Globe Theatre' in London or a music or basketball arena because of the four projector screens.

The discussion of the 'Cube' led to some creative group discussions. For example, some students asked the question: "why is there a preconception that learners need to be in the classroom all the time, or that they need to be seated to listen to the lecture?'. The discussion highlighted that learning could be more effective, if those preconceptions were discounted, when designing a learning space. It was argued that the focus should be on the generation of learning rather than focussing on the teaching. Interestingly, three teacher groups shared a similar view: they suggested that a room with the size of the 'Cube' would be more effective for learning, if it had 'individual inflatable sofas on gentle terraces' rather than rigid seatings. Additionally, they proposed a combination of zones, within the 'Cube', with different functions. These would range from the more informal to the more formal, and from more teacher-centred to more learner-centred.

Similarly, both teachers and students discussed widely the shape of the room, which, it was suggested by the first group of teachers, rather than being square should perhaps be rounded or circular to give a sense of 'openness and to be more inspirational'. This group re-designed the 'Cube' and called it the 'Spherodome' (Figure 2). 


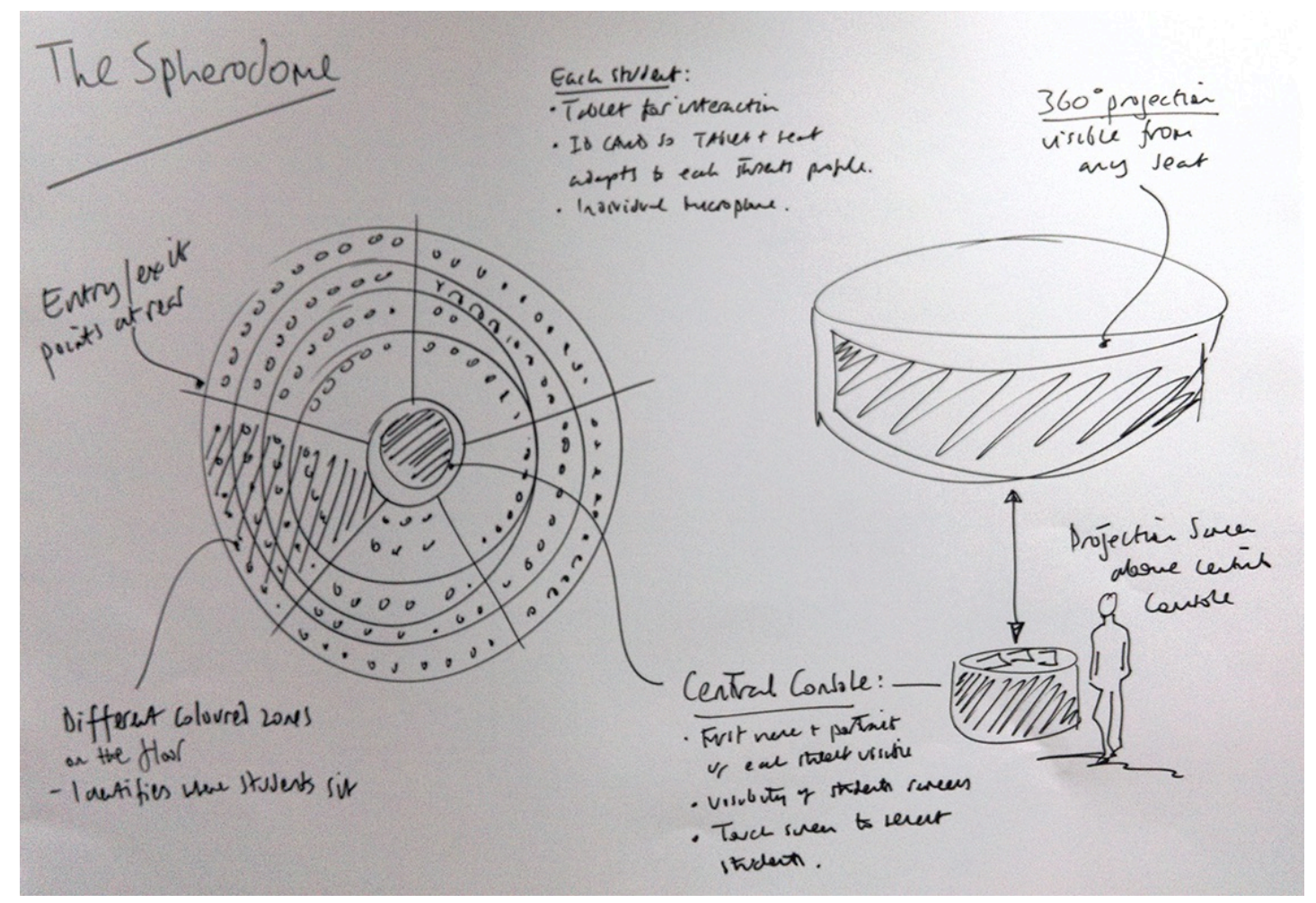

Figure 2. The 'Spherodome', the final output of the redesign of the 'Cube' from the first 'sandpit' with teachers.

Although still allowing for the lecturer's position in the middle of the room, the 'Spherodome' was designed in a rounded shape both in terms of the room layout and the projector screens. It was argued that this would allow for a sense of immersion in the learning process that would not be possible in a square shape. Arguments were made around why there is a trend for designing rooms that have straight lines rather than making use of shapes that encourage more collaboration and participation. The student groups highlighted the importance of having environments that enable a more immersive learning experience, where a lecturer can interact with all students by being able to look at and address all of them without any difficulty. Consequently, the second student group suggested a horseshoe-shaped room, which would enable the students to interact with the lecturer, and the lecturer to walk around the room with ease (Figure 3). 


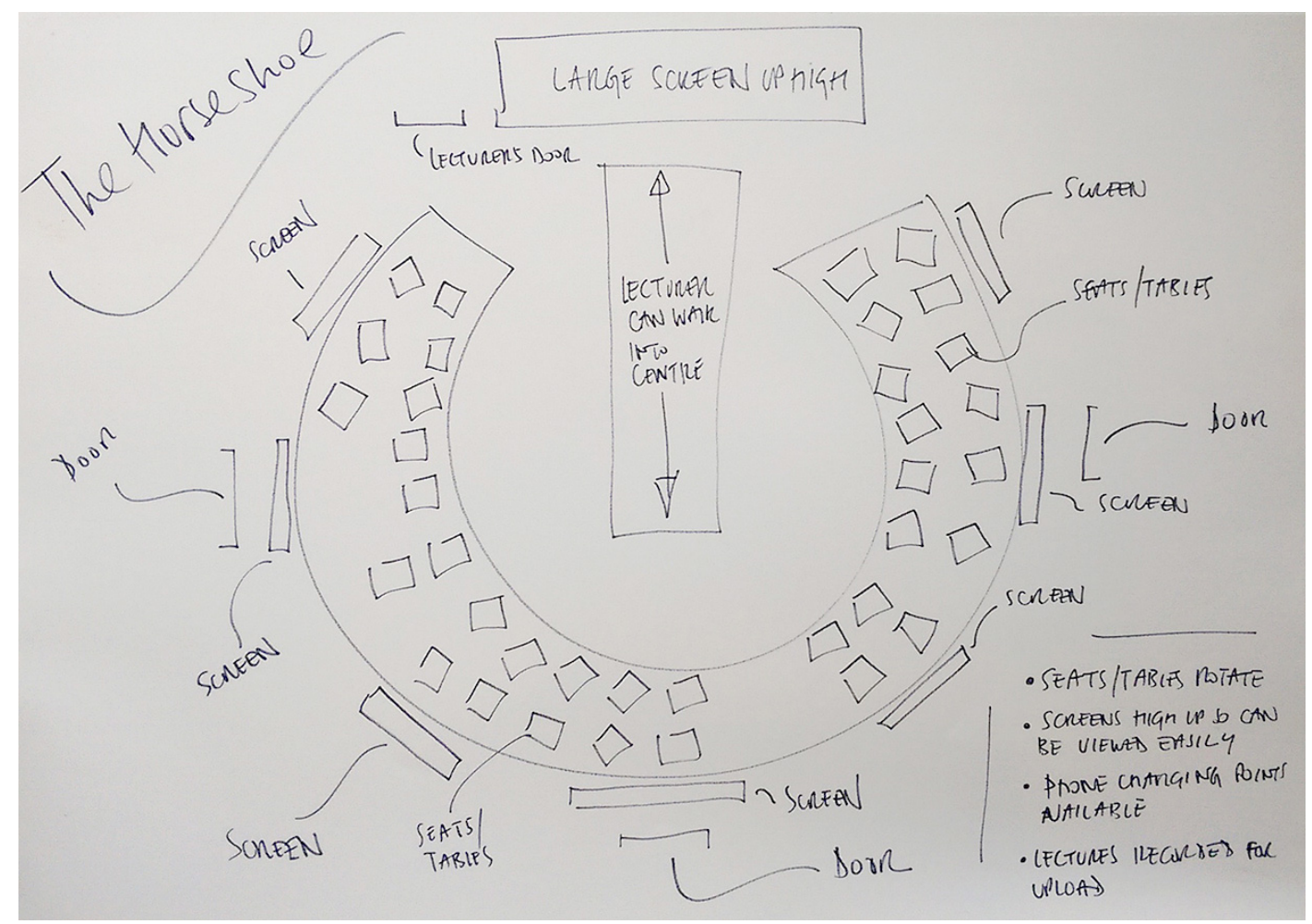

Figure 3. The 'Horseshoe', the final output of the redesign of the 'Cube' from the forth 'sandpit' with students.

The seating was one of the most discussed features of the 'Cube', especially by the student groups who praised the horseshoed seating arrangement as being conducive to closer interactions between lecturer and students. However, many were concerned about the short distance between individual seats and therefore argued in favour of introducing more space between seats to allow for a more comfortable and quiet environment. One student went as far as to say that he would prefer not having students around him, when engaged in individual work or when is listening to a lecture because he could be distracted by his colleagues' conversations and possible text messaging. He would consider being closer to other students but only when undertaking collaborative work. A similar concern was discussed by one group of teachers that argued that the acoustics of normal lecture theatres 'is usually awful', thus suggesting the need for noise-cancelling screens between rows.

\section{The textual function}

The 'textual' function concerns the level of coherence between different learning spaces (Leijon 2016). Only a few references were made to this function. This was perhaps due to the 'Cube' being perceived as a compact, reified space, isolated from any other learning space. However, the question of the size of the room was raised by many participants (both teachers 
and students) as an important and useful element of design coherence between different learning spaces. A commonly held view, among many teachers and students, was that a high number of students in any given learning space would detract from the value of any pedagogic encounter. Subsequently, suggestions were made that a maximum of fifty students would be an ideal number for any classroom size, as this would encourage personalisation and active learning. This finding chimes with research that suggests students prefer being in central positions in smaller rooms where they can establish meaningful learning experiences with the teacher (Park and Choi 2014).

\section{The interpersonal function}

The third communicative function of space, the 'interpersonal', concerns how space can become a motivational factor in the pedagogical process (Leijon 2016). The use of tablets was widely commented on, both by the teachers and the students, as a way to increase motivation and foster interaction. Two groups of teachers suggested that students would prefer to use their own devices to interact with the lecturer, as they are more familiar with them. However, it was argued that students might be open to use generic tablets, provided these tablets allow a 'personal touch', through the use of flexible and customisable software. Another group of teachers argued that students would prefer to use a traditional notepad for writing, as the tablet presence would take too much desk space. Moreover, concerns were raised that the use of tablets to interact with the lecture would detract from the traditional 'Question and Answer' method of teaching, as students would be focussing more on the tablet itself rather than the pedagogical encounter with their teacher and peers.

In contrast, students were enthusiastic about the idea of having embedded tablets, although, in a similar vein to the teachers, some suggested that all devices should have a degree of personalisation/customisation. Many students argued that technology should allow for a separation between personal communications and college work as that did not want to amalgamate friends and family messages with course announcements and assignments. It was suggested that this could be achieved through the use of customisable institutional tablets, which could provide the student with a personal learning environment every time s/he logs-in. Moreover, one group of students and one group sof teachers argued that the use of tablets could be a perfect solution for the students to write in their notebooks, whilst visualising the lecture on their tablet. 
The use of a large projector screen was another point of discussion and considered to be a valuable add-on to a traditional classroom. It was deemed that the existing projection arrangements were not conducive to effective learning, because of their 'small 'size, 'poor image quality', the interference of 'external light' and the difficulty 'to read from a long range'. The use of a projector screen placed higher up was therefore praised, since this would allow everyone to have the same view without any interference from other students at the front of the classroom. A student group went further to suggest that there could be more screens fixed on the four walls in order to ensure that everyone would have the best visual experience possible. This aligns with the research conducted by Beichner et al. (2000) that utilise a range of monitor screens distributed around the room to project image and videos, providing an immersive and collaborative technology-enabled space. Similarly, suggestions were made in two groups of users to the possibility of having an immersive projection on the entirety of the wall behind the lecture or to have a cylindrical projector screen in the middle of the room (Figure 2).

In general, the teacher groups were more interested in discussing the collaborative features of the 'Cube'. For example, they pointed out that the 'Cube' would limit the informality and sense of belonging that smaller rooms usually provide. This led to the idea of having learning pods to enable interaction and small group work. Subsequently, teachers designed a solution that would incorporate two flexible environments within one learning space, one for lecturing and one for group work (Figure 4). The solution proposed (the 'Sofa') would enable better sound conditions for group work, thus augmenting the sense of intimacy in the learning process, with the teacher playing a facilitative role. 


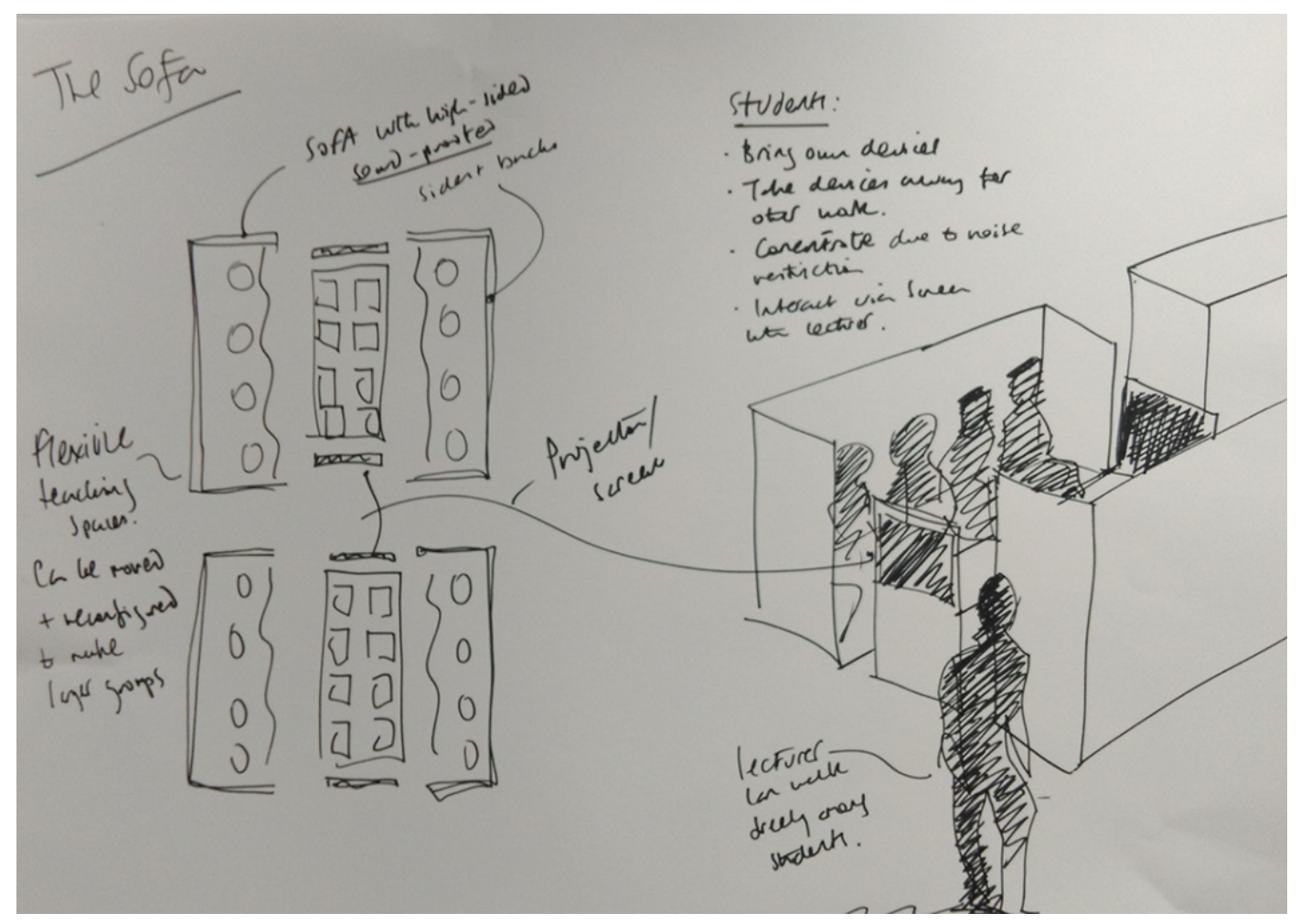

Figure 4. The 'Sofa', the final output of the redesign of the 'Cube' in by teachers group five.

However, not all the teacher groups were completely in agreement that the 'Cube' needed to be necessarily more student-centred. Two groups indicated that the role of the teacher, in the middle of the room, could improve lecturing, especially for those teachers who are more experienced in it. One group even said that experienced teachers could be even more effective in a room such as the 'Cube', as this would enable a better teacher performance - 'it could be a one-man show', one teacher argued. This is an interesting finding as it suggests that lecturing is still perceived by a number of teachers as being quintessential to teaching at university level.

Beyond the value of specific ideas for the design or learning spaces, the discussion above indicates how both students and teachers can formulate well-formed ideas about the design of learning spaces, which can be subsequently used by architects and engineers in planning and constructing new learning spaces functionally and, to an extent, aesthetically. Halliday's theoretical framework, based around three communicative functions (the ideational, the textual and the interpersonal), assisted in the conceptualization and analysis of the data. Although interconnected, these functions provide an insight into the complexity of space design, in which vision, coherence and practical use interrelate for a better fruition of learning spaces by end-users. 
The research also proved that a participatory methodology encourages end-users to reflect on pedagogy in fruitful ways; these reflections, in turn, can helpfully impact on the design and construction of learning spaces, thus bringing pedagogy and space design in a more harmonious alignment.

\section{Reflections on the research process and the way forward}

However interesting these findings may be, we argue that the real value of this piece of research lies in its methodology that helps to capture end-users' ideas about learning spaces in an agentic, experiential and systematic manner. Our research exemplifies what happens if, through participatory design, both teachers and students are given the opportunity to actively engage in the design of learning spaces.

We argue that our approach to learning design mirrors some of the very principles of active learning, which is based on dialogic encounters between different end-users, through discussions and experimentation; the exploitation and use of people's mind-sets for learning purposes; the sharing of power between different stakeholders in the pedagogic process; and pattern making as a way to effective learning (Doyle 2011). Aligning the principles of active learning with the process of designing learning spaces design is, to us, essential in a truly user-centred, more democratic idea of institutional governance (Temple and Barnett 2007). As such, we suggest that our research contributes to current discussions about leadership in terms of the design of learning (Lockwood 2010).

In the future, we intend to widen up our research to other constituencies, within and beyond the end-users. This means engaging a number of stakeholders (including architects, students, teachers, managers and leaders) in an interprofessional dialogue with each other to improve the conceptualisation and management of space design within the higher education sector. Concurrently, we aim to evaluate how design practices resulting from inter-professional dialogues really impact (or not) on pedagogical practices. For us, ultimately, it is not simply a question of 'Which space? Whose space', as the title of this article suggests; it is, rather, one of purposeful spaces for the advancement of pedagogic practices that can truly enhance the students' experience.

\section{Disclosure statement}

No potential conflict of interest was reported by the authors. 
Word count 6022 


\section{References}

Beichner, Robert J. 2014. "History and Evolution of Active Learning Spaces.” New Directions for Teaching and Learning 2014 (137). Wiley Online Library: 9-16.

Beichner, Robert J, Jeffery M Saul, Rhett J Allain, Duane L Deardorff, and David S Abbott. 2000. "Introduction to SCALE-UP: Student-Centered Activities for Large Enrollment University Physics.” Charlotte. http://eric.ed.gov/?id=ED459062.

Bligh, Brett. 2014. "Examining New Processes for Learning Space Design.” In The Physical University: Contours of Space and Place in Higher Education, edited by Paul Temple, 34-57. Oxon: Routledge.

Bligh, Brett, and Charles Crook. 2016. "Learning Spaces : Departure Points for a Spatial Turn in Technology Enhanced Learning." In Technology Enhanced Learning: A Compendium of Research Literature, edited by Erik Duval, Mike Sharples, and Rosamund Sutherland. Springer.

Bligh, Brett, and Ian Pearshouse. 2011. "Doing Learning Spaces Evaluation.” In Re-Shaping Learning: A Critical Reader: A Critical Reader: The Future of Learning Spaces in a Post-Compulsory Education, edited by A Boddington and J Boys, 3-18. SensePublishers.

Bonsignore, Elizabeth, June Ahn, Tamara Clegg, Mona Leigh Guha, Jason C Yip, and Allison Druin Discussant. 2013. “Embedding Participatory Design into Designs for Learning: An Untapped Interdisciplinary Resource?" In Computer-Supported Cooperative Learning Conf. (CSCL 2013). University of Wisconsin - Madison.

Boys, Jos. 2011. Towards Creative Learning Spaces. Oxon, UK: Routledge.

Brooks, D Christopher. 2012. "Space and Consequences: The Impact of Different Formal Learning Spaces on Instructor and Student Behavior." Journal of Learning Spaces 1 (2): 1-16. doi:www.partnershipsjournal.org.

Cerratto-Pargman, Teresa, Sanna M. Järvelä, and Marcelo Milrad. 2012. "Designing Nordic Technology-Enhanced Learning." The Internet and Higher Education 15 (4). Elsevier Inc.: 227-30. doi:10.1016/j.iheduc.2012.05.001. http://linkinghub.elsevier.com/retrieve/pii/S1096751612000267.

Craft, Brock. 2013. "Sketch-Ins: A Method for Participatory Design in Technology-Enhanced Learning." In Handbook of Design in Educational Technology, edited by R. Luckin, S. 
Puntambekar, P. Goodyear, B. Grabowski, J. Underwood, and N. Winters, 92-101. Oxford: Routledge.

Crook, Charles, and Gemma Mitchell. 2012. “Ambience in Social Learning: Student Engagement with New Designs for Learning Spaces." Cambridge Journal of Education 42 (2). Taylor \& Francis: 121-39.

Doyle, Terry. 2011. Learner-Centered Teaching: Putting the Research on Learning into Practice. Stylus Publishing, LLC.

Fereday, Jennifer, and Eimear Muir-Cochrane. 2006. "Demonstrating Rigor Using Thematic Analysis: A Hybrid Approach of Inductive and Deductive Coding and Theme Development." International Journal of Qualitative Methods 5 (1). SAGE Publications: $80-92$.

Frohlich, David M, Christopher Sze Chong Lim, and Amr Ahmed. 2014. "Keep, Lose, Change: Prompts for the Re-Design of Product Concepts in a Focus Group Setting." CoDesign 10 (2). Taylor \& Francis: 80-95. doi:10.1080/15710882.2013.862280. http://dx.doi.org/10.1080/15710882.2013.862280.

Jamieson, Peter. 2003. “Designing More Effective On-campus Teaching and Learning Spaces: A Role for Academic Developers." International Journal for Academic Development 8 (1-2). Taylor \& Francis: 119-33.

Jamieson, Peter, Kenn Fisher, Tony Gilding, Peter G Taylor, and A C F Trevitt. 2000. "Place and Space in the Design of New Learning Environments." Higher Education Research and Development 19 (2). Taylor \& Francis: 221-36.

Jessop, Tansy, Laura Gubby, and Angela Smith. 2012. "Space Frontiers for New Pedagogies: A Tale of Constraints and Possibilities." Studies in Higher Education 37 (2): 189-202. doi:10.1080/03075079.2010.503270. http://www.tandfonline.com/doi/abs/10.1080/03075079.2010.503270.

JISC - Joint Information Systems Committee. 2006. "Designing Spaces for Effective Learning." Bristol. http://www.jisc.ac.uk/media/documents/publications/learningspaces.pdf.

Johnson, L., S. Adams Becker, V. Estrada, and A. Freeman. 2015. "Horizon Report.” Austin, Texas. doi:978-0-9906415-8-2.

Kehm, Barbara M, and Ulrich Teichler. 2013. The Academic Profession in Europe: New 
Tasks and New Challenges. Vol. 5. Springer Science \& Business Media.

Kemmis, S., R. McTaggart, and R. Nixon. 2014. Critical Participatory Action Research. Singapore: Springer.

Könings, Karen D., Tina Seidel, and Jeroen J. G. Merriënboer. 2014. "Participatory Design of Learning Environments: Integrating Perspectives of Students, Teachers, and Designers." Instructional Science 42 (1): 1-9. doi:10.1007/s11251-013-9305-2.

http://link.springer.com/10.1007/s11251-013-9305-2.

Kress, Gunther R, and Theo Van Leeuwen. 2005. Reading Images: The Grammar of Visual Design. Psychology Press.

Leijon, Marie. 2012. “The Room in Higher Education-a Space for Learning?” In 3rd International Conference Exploring Learning Environments, 104-5. Copenhagen: Aalborg Universitet, Köpenhamn. . 2016. "Space as Designs for and in Learning: Investigating the Interplay between Space, Interaction and Learning Sequences in Higher Education." Visual Communication.

Lockwood, Thomas. 2010. Design Thinking: Integrating Innovation, Customer Experience, and Brand Value. Skyhorse Publishing, Inc.

Melhuish, Clare. 2011. "Methods for Understanding the Relationships between Learning and Space." In Re-Shaping Learning: A Critical Reader, edited by A Boddington and J Boys, 19-31. SensePublishers.

Miller-Cochran, Susan, and Dana Gierdowski. 2013. "Making Peace with the Rising Costs of Writing Technologies: Flexible Classroom Design as a Sustainable Solution.” Computers and Composition 30 (1). Elsevier: 50-60.

Muller, Michael J., and Allison Druin. 2003. "Participatory Design: The Third Space in HCI." Human-Computer Interaction: Development Process. Vol. 4235.

Neary, M, Andrew Harrison, Giles Crellin, and Nayan Parekh. 2010. "Learning Landscapes in Higher Education.” Lincoln. doi:978-0-9564797.

http://learninglandscapes.blogs.lincoln.ac.uk/files/2010/04/FinalReport.pdf.

Oblinger, Diana. 2006. Learning Spaces. Vol. 2.

Park, Elisa L., and BoKeum Choi. 2014. “Transformation of Classroom Spaces: Traditional 
versus Active Learning Classroom in Colleges.” Higher Education 68 (5). Springer

Netherlands: 749-71. doi:10.1007/s10734-014-9742-0.

http://dx.doi.org/10.1007/s10734-014-9742-0.

Pederby, Duncan. 2014. “A New Frontier in Learning." In Active Learning Spaces and Technology, edited by Duncan Pederby, 11-16. Worcester: DroitwichNet.

Radcliffe, David. 2009. “A Pedagogy-Space-Technology (PST) Framework for Designing and Evaluating Learning Places." In Proceedings of the Next Generation Learning Spaces 2008 Colloquium, edited by David Radcliffe, Hamilton Wilson, Derek Powell, and Belinda Tibbetts, 9-16. Brisbane: University of Queensland. http://www.uq.edu.au/nextgenerationlearningspace/UQ Next Generation Book.pdf.

Ravelli, Louise J. 2000. "Beyond Shopping: Constructing the Sydney Olympics in ThreeDimensional Text." Text-Interdisciplinary Journal for the Study of Discourse 20 (4): 489-516.

Reushle, Shirley. 2012. "Designing and Evaluating Learning Spaces: PaSsPorT and DesignBased Research.” In Physical and Virtual Learning Spaces in Higher Education: Concepts for the Modern Learning Environment, edited by M. Keppell, K. Souter, and M. Riddle, 87-101. Hershey, PA: IGI Global.

Schuler, Douglas, and Aki Namioka. 1993. Participatory Design: Principles and Practices. Edited by Douglas Schuler and Aki Namioka. Oxon, UK: CRC Press.

Scott-Webber, L., J. Branch, BartholomewP., and C. Nygaard. 2014. "Practising Learning Space Design.” In Learning Space Design in Higher Education, edited by C. Nygaard, J. Branch, P. Barthlomew, and L. Scott-Webber. Libri Publishing.

Scott-webber, Lennie. 2013. "The Story of Verb ${ }^{\mathrm{TM}}$ : Innovative Design Fit for Education 21st Century Learning Needs." International Journal of Designs for Learning 4 (2): 30-40. doi:27. https://scholarworks.iu.edu/journals/index.php/ijdl/article/view/3964.

Sherringham, S J, and S C Stewart. 2011. "Fragile Constructions: Processes for Reshaping Learning Spaces.” In Reshaping Learning, edited by A. Boddington and J. Boys, 10518. Sense Publishers.

Stenglin, Maree Kristen. 2009. "Space Odyssey: Towards a Social Semiotic Model of ThreeDimensional Space." Visual Communication 8 (1). SAGE Publications: 35-64.

Temple, Paul. 2008. "Learning Spaces in Higher Education: An Under-researched Topic." 
London Review of Education 6 (3). Taylor \& Francis: 229-41.

Temple, Paul, and Ronald Barnett. 2007. "Higher Education Space: Future Directions." Planning for Higher Education 36 (1). ERIC: 5-15.

Van Note Chism, Nancy. 2006. "Challenging Traditional Assumptions and Rethinking Learning Spaces.” In Learning Spaces, edited by Diana G. Oblinger. Washington DC: Educause.

Williams, Sam. 2014. "Integrating Student Pespectives into the Development of Learning Spaces at the University of Lincoln." In Active Learning Spaces and Technology, edited by Duncan Peberdy, 45-49. Droitwhich.

Woolner, Pamela. 2009. "Building Schools for the Future through a Participatory Design Process: Exploring the Issues and Investigating Ways Forward.” In BERA 2009. Manchester. 


\section{Appendix one}

Example of the script used during the contextualisation narrative of the 'Cube' delivered to teachers during the 'sandpits'. As the narrator was telling the story of 'John Lock' images similar to Figure 1 were being shown in the wall.

\section{1}

My name is John Lock and I am a Professor of Archaeology at Bloom's University. I am here today to introduce you a new lecture room I am teaching on. The name of this lecture room is the 'Cube' and it has capacity for 376 seats.

The name of the room is the 'Cube' I was told because of the shape it has ... It looks like a square but at the same time it is very high and it suggests that we are literally inside a close cube.

\section{2}

Students are able to come in from every segment of the Cube hence they will not interrupt me when I am lecturing and since they are coming from the back they will also not interrupt their fellow students.

\section{3}

I am teaching in the box which is what we called the teaching podium.

The interesting component of the box is that rather than having a monitor and a computer I have at my disposal a kind of a tablet-based forty inches mixing console, which enables me to conduct a set of very cool interactions with the four large projected screens on top of my head.

The console allows me to select four different channels for each or for all projector screens. I can select:

- the presentation channel (the power point file or my desktop);

- the social media channel, which is pre-configured to Twitter, Facebook, Youtube, Diigo and other social media widgets that I never heard about; 
- the whiteboard which enables me to write down in the console as I was doing in a normal whiteboard and show every interaction in the screen;

- and finally a live screen channel. In this channel I can either select one student tablet channels (through an ID they give-me when I ask) or show the lecture capture camera (all the classrooms inside the 'Cube' are recorded through a lecture capture system). I also have the possibility of levelling the sound of the microphones (for each stand there is one microphone as there is one for the box), the temperature and the lights of the room. However, the lights, temperature and sound are set to be automatic adapting to the natural light coming from outside, the number of students and/or the weather and the level of sound produced by students.

\section{5}

Because it is all tablet-based its appearance changes (rotates) according to the place where I am so it is easy for me to interact with the console.

\section{6}

The main advantage of the 'Cube' is that wherever I am students can see me perfectly and so can I, hence it is not so easy for a student to be disengaged completely from the classroom without being noticed. The other is that students are closer to me (no more than ten meters), which gives me a sense of a small classroom teaching.

Students seating is also very innovative. Their chairs adapt to students' position and posture. So besides being very comfortable (sometimes too much - I had more than once students sleeping) they rotate (360 degrees) but also adapt in height for adapting to group work of two or four students. Students have a place just under the seat where they can put their coats or bags and they also have a power outlet where they can plugin their mobile devices. 
In each table students have incorporated a seven-inches tablet, which enables them to interact with the whiteboard and the social media channel. They also have a space for their own devices.

The students' table is also very different from a traditional one. First it also rotates to 360 degrees and adapts in height so to adjust to group work of two or four, but rather than rotating in its own axis (as the seat) it rotates as a carrousel with the seating as it axis.

One feature I didn't refer about yet is the number of windows. The 'Cube' as windows with $2 \mathrm{~m}$ height above all the four walls but rather than being in eyesight, they are above students' heads. I was told that the reason for it is that students won't distract themselves looking outside but it serves the purpose of having natural light and fresh air when needed. I can also turn the windows darker to prevent the sun from coming every time I want, and especially if I want to show a video. I can also control this from my console. 